CONCISE REPORT

\title{
Willingness of patients with ankylosing spondylitis to pay for inpatient treatment is influenced by the treatment environment and expectations of improvement
}

\author{
A Boonen, J L Severens, A van Tubergen, R Landewé, G Bonsel, D van der Heijde, Si van der \\ Linden
}

Ann Rheum Dis 2005;64:1650-1652. doi: 10.1136/ard.2005.038786

\begin{abstract}
Objective: To assess the willingness to pay (WTP) for treatment in a spa resort of patients with ankylosing spondylitis (AS) and to assess if the experience of a spa influences the WTP.

Methods: 120 patients participating in a randomised trial comparing 3 weeks' treatment in a spa resort in Austria or in the Netherlands with a control group completed a WTP questionnaire before and after spa treatment. Patients indicated on a payment card the maximal co-payment they wanted to contribute for three scenarios that included (a) two levels of improvement in pain and stiffness and (b) two treatment environments: a rehabilitation hospital and a spa resort.

Results: At baseline, patients wanted to contribute more for the same improvement after treatment in a spa resort compared with a rehabilitation hospital $(p<0.003)$, and were prepared to pay more when expected effects were higher $(p<0.001)$. No differences were found between men and women, pain, or income. After the trial none of the treatment groups showed a change in their WTP.

Conclusion: The WTP of patients with AS for inpatient treatment is influenced by the treatment environment and the expected improvement. Experiencing treatment in a spa resort does not influence the co-payment.
\end{abstract}

l: patients with ankylosing spondylitis (AS), a recent randomised controlled trial showed that spa exercise treatment had beneficial effects for up to 9 months on pain and stiffness, physical function, and wellbeing. ${ }^{1}$ Although there were additional costs, the incremental costutility ratio of spa treatment compared with usual treatment was acceptable, varying from $€ 7122$ to $€ 24$ 200/quality adjusted life year. ${ }^{2}$ Notwithstanding, it is debated whether spa exercise treatment for AS should be (partly) reimbursed because it is considered a luxury and not basic treatment. Therefore, it is of interest to know if patients are prepared to contribute personally as a reflection of their personal preference. In this study, patients were asked about the contribution they would pay for a sure and predefined improvement in pain and stiffness after 3 weeks' inpatient treatment in a spa resort as compared with 3 weeks' treatment in a rehabilitation hospital. Variables influencing the willingness to pay (WTP), including the experience of spa treatment, were analysed.

\section{PATIENTS AND METHODS}

\section{Patients}

One hundred and twenty patients with confirmed AS were randomly allocated into three groups of 40 patients. The two intervention groups were treated with a 3 week inpatient programme at a spa resort, one in Bad Hofgastein in Austria and the second in a local resort in the Netherlands. The control group continued with non-steroidal anti-inflammatory drugs and weekly physical exercises at home. ${ }^{12}$

\section{Assessments}

Assessments were performed at baseline (2 weeks before randomisation and intervention; $\left.\mathrm{T}_{-2 \mathrm{~W}}\right)$, and at $4\left(\mathrm{~T}_{4 \mathrm{~W}}\right)$, and 40 weeks $\left(\mathrm{T}_{40 \mathrm{w}}\right)$ after the start of the intervention. At baseline, patients were asked about their personal gross monthly income (no personal income; $<€ 3250$; $\geqslant € 3250$ but $<€ 4500$; $\geqslant € 4500)$. Several questionnaires were completed, including the Bath AS Functional Index (BASFI; 0-10; higher values worse functioning), ${ }^{3}$ the AS Quality of Life (ASQoL; 018 higher values worse quality of life $)^{4}$ and the EuroQol 5 dimensions (EQ-5D: -0.3 to 1.0: higher values better utility). ${ }^{5}$ The ASsessment in AS (ASAS) $20 \%$ response was calculated at each post-intervention evaluation. ${ }^{6}$ At baseline, $\mathrm{T}_{4 \mathrm{w}}$, and $\mathrm{T}_{40 \mathrm{w}}$ patients completed a WTP questionnaire (see appendix, available on the website at http://www.annrheumdis.com/supplemental)). Firstly, patients had to rate the present pain and stiffness on a numeric rating scale $(0$, no pain to 4 , very severe pain). Next patients had to indicate the maximum co-payment they were prepared to contribute to the health insurance for three treatment scenarios:

- One level of improvement in personal pain and stiffness (on the 0-4 scale) during 1 year after a 3 week stay in a local rehabilitation hospital

- One level of improvement after a 3 week stay in a spa resort

- Two levels of improvement after a 3 week stay in a spa resort.

For each scenario, patients had to decide between six copayment levels on a payment card: $€ 0, € 112, € 225, € 450$, $€ 900$, or $€ 1800$.

\section{Statistical analyses}

Test-retest reliability of the WTP was assessed by $\kappa$ of agreement in the control group at $\mathrm{T}_{-2 \mathrm{w}}$ and $\mathrm{T}_{4 \mathrm{w}}$. The $\mathrm{T}_{-2 \mathrm{w}}$ evaluation was used to describe the proportion of patients prepared to pay each of the co-payment levels. Differences in WTP ${ }^{1}$ between improvement after treatment in a rehabilitation hospital as opposed to the spa resort, ${ }^{2}$ between improvement of two levels in pain and stiffness as opposed to one level, ${ }^{3}$ and before and after spa treatment in the intervention groups were tested by Wilcoxon signed ranks test. Differences in WTP between men and women, level of

Abbreviations: AS, ankylosing spondylitis; ASAS, ASsessment in AS; ASQoL, AS Quality of Life; BASFI, Bath AS Functional Index; EQ-5D, EuroQol 5 dimensions; WTP, willingness to pay 
Table 1 The maximal co-payment that patients (\%) are definitely prepared to pay for 1 year's improvement in pain and stiffness after a 3 week inpatient treatment for three scenarios

\begin{tabular}{lrrrrrr}
\hline Scenario & $€ 0$ & $€ 112$ & $€ 225$ & $€ 450$ & $€ 900$ & $€ 1800$ \\
\hline (1) Rehabilitation hospital; 1 level of improvement* & 11 & 24 & 44 & 16 & 3 & 2 \\
(2) Spa resort; 1 level of improvement & 8 & 15 & 42 & 28 & 6 & 3 \\
(3) Spa resort; 2 levels of improvement & 5 & 9 & 31 & 32 & 17 & 7 \\
\hline *Improvement in pain and stiffness. & & & & & &
\end{tabular}

income, or the level of pain and stiffness were assessed by Mann-Whitney or Kruskal-Wallis tests. Multivariate ordinal logistic regression determined the adjusted influence of age, sex, income, level of pain and stiffness, and (if applicable) intervention ${ }^{1}$ on each scenario and on change in WTP $^{2}$ (similar, lower, or higher contribution) after the intervention. Treatment response at $\mathrm{T}_{4 \mathrm{~W}}$ was defined firstly, as at least one level of improvement in pain and stiffness on the $0-4$ scale of the questionnaire and, secondly, as an ASAS $20 \%$ response.

\section{RESULTS}

Eighty eight $(73 \%)$ of the 120 participants were male, mean (SD) age 48 (9.9) years and mean (SD) disease duration 11 (5.7) years. The mean (SD) BASFI was 4.5 (2.0), ASQoL 7.8 (4.5), and EQ-5D $0.66(0.21)$. At $\mathrm{T}_{-2 \mathrm{w}} 12 \%$ rated pain and stiffness as mild, $61 \%$ moderate, $26 \%$ severe, and $1 \%$ very severe. Eight per cent had no income, 25\% <€3250; 46\% between $€ 3250$ and $<€ 4500$, and $21 \%$ more than $€ 4500$ / month. At the $\mathrm{T}_{-2 \mathrm{w}}$ and $\mathrm{T}_{40 \mathrm{w}}$ evaluation, respectively, 15 $(13 \%)$ and $27(23 \%)$ patients rated their level of pain and stiffness as 0 (no pain) or 1 (mild pain) and could therefore not score the third WTP scenario asking about maximal contribution for two levels of improvement. They did not differ in other characteristics from the patients who completed all three scenarios. There were no other missing values. The test-retest reliability $(\kappa)$ of the WTP was 0.53 $(\mathrm{p}<0.001), 0.43(\mathrm{p}<0.001)$, and $0.56(\mathrm{p}<0.001)$ for scenarios (1) to (3). Table 1 presents the WTP at baseline for the three different scenarios.

Thirty four per cent of patients were willing to contribute more for the same effect after treatment in a spa resort than after treatment in a rehabilitation hospital $(\mathrm{p}<0.003)$ (fig 1A). For treatment in a spa resort, $43 \%$ of patients were prepared to pay more if the expected improvement in pain was higher (two levels compared with one level) $(p<0.001)$ (fig 1B). No differences were found in the WTP for men or women, working status, income, level of pain, or experienced quality of life (ASQol or EQ-5D) either in univariate or multivariate analyses. At $\mathrm{T}_{4 \mathrm{w}}, 32 \%$ (Austria) and $28 \%$ (Netherlands) of patients compared with $15 \%$ of controls had at least a one level of improvement in pain and stiffness (between-group $\mathrm{p}=0.2$ ). The ASAS $20 \%$ comprises five outcome domains and could better distinguish between the treatment groups, showing responses of 33\% (Austria) and $35 \%$ (Netherlands) compared with $10 \%$ for controls (between-group $\mathrm{p}=0.02$ ). Wilcoxon signed ranks test did not show a difference in the WTP at $\mathrm{T}_{40 \mathrm{w}}$ compared with $\mathrm{T}_{-2 \mathrm{~W}}$ in any of the intervention groups. Multivariate ordinal regression analyses confirmed that there was no influence of treatment assignment or response to treatment on the change in WTP after the intervention.
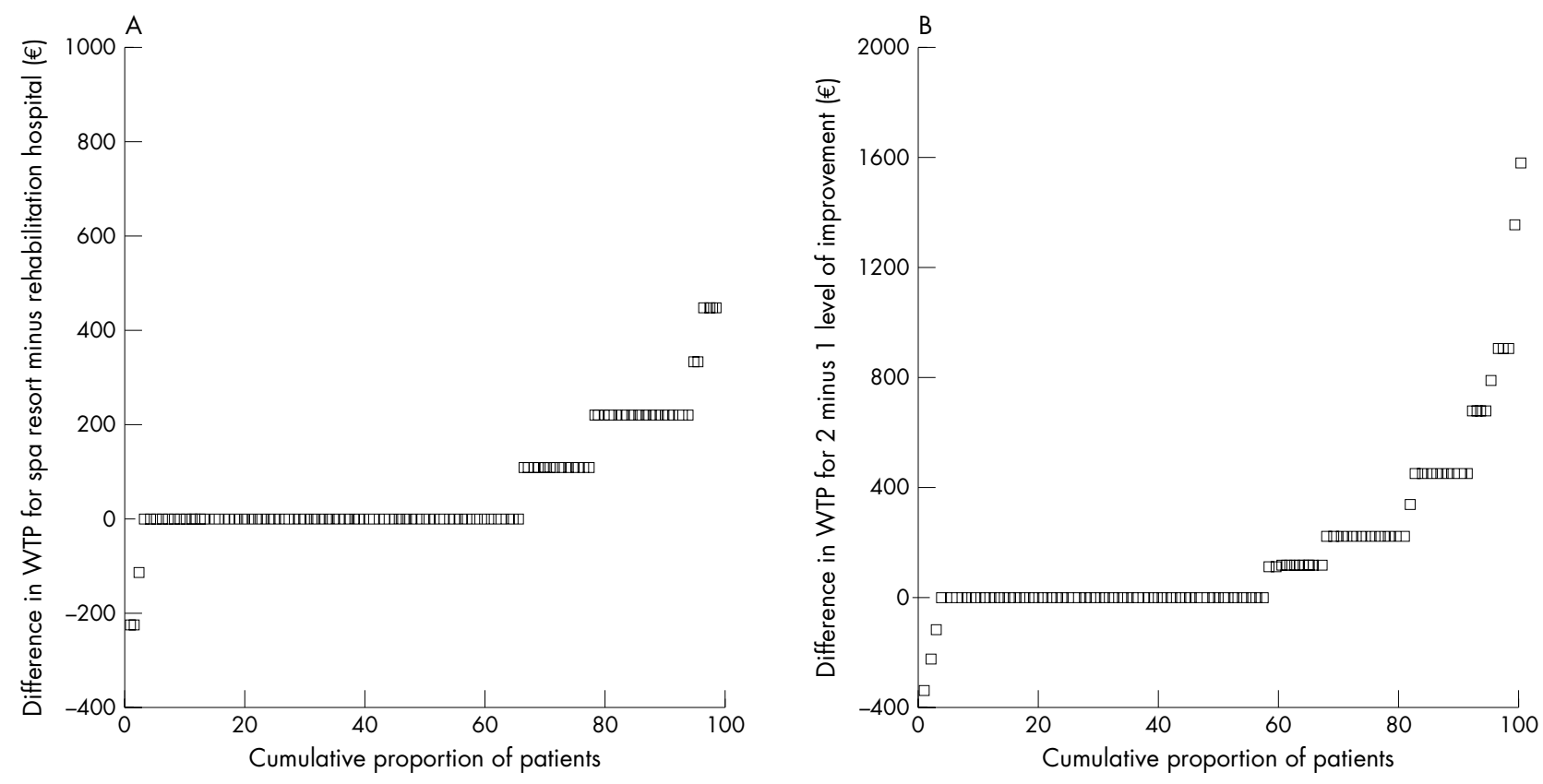

Figure 1 (A) Difference in WTP for improvement through a stay in a rehabilitation hospital as opposed to a spa resort (y axis) plotted against the cumulative proportion of patients reporting that difference in WTP ( $x$ axis). (B) Difference in WTP for a spa treatment for two levels of improvement in pain compared with one level (on a scale from 0 to 4 ) (y axis) plotted against the cumulative proportion of patients reporting that difference in WTP(x axis). 


\section{DISCUSSION}

To gain insight into the WTP of patients with AS for an inpatient spa exercise treatment, a simple WTP questionnaire with fixed payment levels was added alongside a randomised controlled trial evaluating spa exercise treatment. ${ }^{12}$ Before the spa treatment, $34 \%$ of patients were willing to contribute a higher co-payment for a similar effect on pain and stiffness after treatment in a spa resort compared with treatment in a rehabilitation hospital. In addition, 43\% stated they were willing to contribute more for better relief in pain and stiffness after the spa treatment. Whereas $21 \%$ of patients were prepared to contribute $€ 450$ or more for one level of improvement in pain and stiffness during 1 year after a stay in a rehabilitation hospital, $37 \%$ and $56 \%$ of patients, respectively, were prepared to contribute $€ 450$ or more for one or two levels of improvement after a spa treatment. Although it is easy to understand that patients are prepared to pay more for a better effect of the treatment, it is less clear what the incentive is to pay more for treatment in a spa resort rather than in a rehabilitation hospital. Probably, the nonmedical environment is the major reason for the personal contribution. The specific attributes constituting the treatment environment were not explored.

The absence of a relationship between a WTP and income might be surprising. On the other hand, also for nonhealthcare goods there is no absolute relationship between expenditure and income. It was striking that the WTP of a predefined relative (one level) gain in pain and stiffness was independent of the individual absolute level of pain and stiffness. Apparently, patients value the healthcare programme independently from their personnel health state. The questionnaire asked about the sure and predefined effect of the spa treatment. This might explain why no change in WTP was found in patients responding to spa treatment. The real effect does not confound the relationship between the presumed effect and the WTP.

Certainly, this WTP questionnaire has limitations. ${ }^{7-9}$ The absolute co-payment should be interpreted with caution. ${ }^{10}$ In the close ended payment card method subjects avoid the extremes and tend to provide answers in the middle of the scale. In addition, the payment cards may have a ceiling effect, which might further explain the absence of the effect of clinical response on the WTP. Open questions or bidding games probably provide better estimates of the absolute WTP. Two limitations relate to the study design. Firstly, the small sample might have caused a non-detection of small differences in WTP between subgroups. Secondly, the study applies to patients volunteering to take part in a spa exercise trial and therefore likely recognise the importance of exercise programmes. Clearly, these patients are prepared to pay extra for the programme in a spa resort compared with a rehabilitation hospital.

In conclusion, this questionnaire developed to assess the WTP of patients with AS for a spa exercise treatment was easy for the patients to complete. It showed that a WTP depends on the treatment environment and the expected improvement in clinical symptoms but is independent of health state and not influenced by the experience of spa treatment.

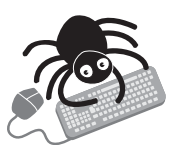

An appendix showing the "Willingness to contribute financially to rehabilitation in a spa resort" can be found on the website at http://www.annrheumdis. com/supplemental

\section{Authors' affiliations}

A Boonen, A van Tubergen, Department of Internal Medicine, Division of Rheumatology, University Hospital Maastricht, The Netherlands J L Severens, Department of Health Organisation, Policy and Economics, University Maastricht, The Netherlands

R Landewé, D van der Heijde, Sj van der Linden, Department of Internal Medicine, Division of Rheumatology, University Hospital Maastricht and Caphri Research Institute, The Netherlands

G Bonsel, Department of Clinical Epidemiology, Amsterdam Medical Centre, Amsterdam, The Netherlands

Correspondence to: $\operatorname{Dr}$ A Boonen, Department of Internal Medicine, Division of Rheumatology, University Hospital Maastricht, PO Box 5800, 6202 AZ Maastricht, The Netherlands; aboo@sint.azm.nl

Accepted 28 March 2005

\section{REFERENCES}

1 van Tubergen A, Landewe R, van der Heijde D, Hidding A, Wolter N, Asscher $M$, et al. Combined spa-exercise therapy is effective in patients with ankylosing spondylitis: a randomized controlled trial. Arthritis Rheum 2001:45:430-8.

2 Van Tubergen A, Boonen A, Landewe R, Rutten-Van Molken M, Van Der Heijde D, Hidding A, et al. Cost effectiveness of combined spa-exercise therapy in ankylosing spondylitis: a randomized controlled trial. Arthritis Rheum 2002;47:459-67.

3 Calin A, Jones SD, Garrett SL, Kennedy LG. Bath Ankylosing Spondylitis Functional Index. Br J Rheumatol 1995;34:793-4.

4 Doward LC, Spoorenberg A, Cook SA, Whalley D, Helliwell PS, Kay U, et al. Development of the ASQoL: a quality of life instrument specific to ankylosing spondylitis. Ann Rheum Dis 2003;62:20-6.

5 Group TE. EuroQol-a new facility for the measurement of health-related quality of life. Health Policy 1990;16:199-208.

6 Anderson JJ, Baron G, van der Heijde D, Felson DT, Dougados M. Ankylosing spondylitis assessment group preliminary definition of short-term improvement in ankylosing spondylitis. Arthritis Rheum $2001 ; 44: 1876-86$.

7 Bayoumi AM. The measurement of contingent valuation for health economics. Pharmacoeconomics 2004;22:691-700.

8 Diener A, O'Brien B, Gafni A. Health care contingent valuation studies: a review and classification of the literature. Health Econ 1998;7:313-26.

9 O'Brien B, Gafni A. When do the "dollars" make sense? Toward a conceptual framework for contingent valuation studies in health care. Med Decis Making 1996; 16:288-99.

10 Frew EJ, Wolstenholme JL, Whynes DK. Comparing willingness-to-pay: bidding game format versus open-ended and payment scale formats. Health Policy 2004;68:289-98. 